\title{
Experimental Contribution Concerning the Effect of Carbonation Reaction on the Oxygen Permeability of Concrete
}

\author{
Mohamed El Ghazali Belgacem ${ }^{1,3^{*}}$, Aissa Talah$^{1}$, Rui Neves$^{2}$, Farid Belhamel $^{3}$, Smail Kechidi $^{4}$ \\ ${ }^{1}$ University of Science and Technology Houari Boumedienne, USTHB, Algiers, Algeria \\ ${ }^{2}$ Barreiro Technology School, Polytechnic Institute of Setubal, R. Américo da Silva Marinho, 2939-001 Barreiro, Portugal \\ ${ }^{3}$ National Center of Studies and Integrated Research on Building Engineering, CNERIB, Algiers, Algeria \\ ${ }^{4}$ Faculty of Engineering, University of Porto, Rua Dr. Roberto Frias s/n, 4200-465 Porto, Portugal \\ * Corresponding author, e-mail: m.belgacem@cnerib.edu.dz
}

Received: 17 January 2020, Accepted: 03 August 2020, Published online: 21 September 2020

\begin{abstract}
Reinforced concrete (RC) structures are prone to steel corrosion that affects their service life. The two main processes, involved in the destruction of the steel-concrete self-protection are the carbonation and the penetration of chlorides. Understanding the behavior of these degrading phenomena is of paramount importance to enhance the field of predicting the service life of RC structures. In this investigation, a total number of 54 cylindrical specimens $\left(150 \times 100 \mathrm{~mm}^{2}\right)$ and 54 cubic specimens $(100 \times 100$ $\mathrm{mm}^{2}$ ) from six different concrete mixtures covering a range of water-to-cement ratio (w/c) between 0.76 and 0.36 was tested. The effect of the carbonation reaction on the concrete oxygen permeability (assessed by a recent method), compressive strength, and weight has been investigated. The obtained data were analyzed to establish correlations to predict the oxygen permeability of non-carbonated concrete with concrete characteristics such as w/c ratio and compressive strength. Test results show good correlations. The results of the accelerated carbonation test showed that compressive strength increases with carbonation. Concerning the effect of carbonation reaction on concrete oxygen permeability which is the main goal of this paper, test results showed that carbonation considerably affects the concrete permeability. This result was observed for all concrete mixtures. Moreover, the relationship between carbonation depth and concrete oxygen permeability in ordinary concrete differed than high performance concrete. Furthermore, the increase of the oxygen permeability observed after the carbonation has been justified by the analysis of the Scanning Electron Microscopy images that show the formation of larger pores in comparison with noncarbonated concrete.
\end{abstract}

Keywords

carbonation, compressive strength, oxygen permeability

\section{Introduction}

Reinforced concrete (RC) is a composite material in which concrete low tensile strength and ductility are counter reacted by the inclusion of reinforcement bars having tensile strength and ductility. The durability of RC structures will be determined by the ability of these materials to resist the different types of degradations during their service life [1]. In many countries, in the purpose of achieving the required service life, repairing and strengthening $\mathrm{RC}$ structures requests a huge annual budget $[2,3]$. The most common deterioration mechanism that causes the reduction of the durability of the RC structures is the corrosion of the reinforcement bars $[4,5]$.
Over recent years, researchers have carried out several experimental studies aiming at understanding the corrosion patterns.

Carbonation and chloride penetration are the major factors that cause the corrosion of the reinforcement bars in RC elements $[1,6]$. Steel corrosion induced by carbonation reaction may lead to concrete cover cracking

and spalling due to the larger volume that the rust of the corroded steel bars occupies, while chloride ions attack punctually the steel bars (pitting) in which it causes the loss of the mechanical strength of steel bars $[1,4,7]$. In recent decades, global warming has dramatically 
increased the atmospheric carbon dioxide concentration to which the RC structures are exposed. As a consequence, the concrete carbonation has become one of the most critical issues related to the durability of the RC structures in urban environment [8].

The concrete carbonation reaction is a physical-chemical process that starts when the $\mathrm{CO}_{2}$ diffuses into the pore system $[4,9,10]$ and ends with the formation of calcite [11-13] along with the decrease of the $\mathrm{pH}$ which leads to steel corrosion onset [1,8]. In natural conditions, it takes several years for a carbonation front progress of few centimeters, in regular concrete. To anticipate concrete behavior concerning carbonation, accelerated tests are carried out. In these tests, optimal temperature and relative humidity conditions are provided, together with high $\mathrm{CO}_{2}$ concentration. According to Fick's diffusion law, the carbonation rate varies with the square root of $\mathrm{CO}_{2}$ concentration. Besides this, other sources of discrepancy shall be considered when extrapolating from accelerated testing to behavior under natural conditions. The temperature and, especially, the relative humidity and the possibility of contact with water (concrete saturation) must be considered. Then, the presence of correction factors in models to predict natural carbonation, based on accelerated carbonation results, is quite common [14-16], ensuring a proper transposition from accelerated testing to natural conditions.

Although the different steps of carbonation process are discussed in detail by the scientific community, investigating the effect of the carbonation reaction on the permeability properties, as well as the assessment of the carbonation via other indicators of performance or durability such as compressive strength, permeability, porosity/capillarity, require further researches within the aim of providing more data.

The effect of carbonation on the concrete permeability has been studied by several researchers. Test results showed that water permeability of fully carbonated cement grout decreased by 3 to 6 orders of magnitude in comparison with non-carbonated cement grout specimens [17]. These results were later validated by Song and Kwon [18]. On the other hand, Thiery [19] has found trends, water permeability increases with carbonation, while for the specimens where the oxygen permeability test was assessed, the results of permeability were not uniform with an increasing in some mixtures whilst decreased in others. The same observation has been stated by Russel et al. [20] in different concrete mixtures where, gas was used to measure concrete permeability with a general trend of increasing of the permeability results. Russel also concluded that the permeability can be related to the carbonation rate.

Furthermore, the development of non-destructive test method to assess in-situ concrete permeability such as Torrent method for air permeability [21] allows researchers to have the possibility to indirect assess the concrete carbonation [6]. In the same direction, the literature reported that a relationship exists between carbonation depth and oxygen permeability results measured at 28 days [22]. Hence, it can be seen that permeability of concrete is an important indicator to foresee concrete durability and based on the aforementioned research findings studying it can be seen that the effect of carbonation on the concrete permeability is not a settled subject which needs more investigation, firstly, in order to clarify the controversy that exists and secondly, to enhance the field of assessing the durability of the RC structures through other indicators which has gained momentum in the recent years.

However, it is worth to mention that the real durability of the RC structures is influenced by load effect that play a key role in the penetration of the aggressive agent as $\mathrm{CO}_{2}$ and this is due to the increase of the tensile micro-cracking in concrete matrix [23, 24]. According to [24] the rate of carbonation under tensile stress increases with increasing applied load therefore, In order to predict carbonation rate of concrete while exposed to an external load a correction factor can be adopted when the rate of carbonation has been measured as function of time on concrete samples without load. Castel et al. [23] proposed a relationship that allowed the prediction of the increase of carbonation depth using a tensile steel stress criterion $\left(\sigma_{\mathrm{s}}\right)$.In the same context, den Heede et al. [25] considering as deterioration threshold the steel depassivation found that service life for the uncracked concrete is greatly higher than concrete with a crack $0.3 \mathrm{~mm}$ wide and with a depth of $25 \mathrm{~mm}$ from the $50 \mathrm{~mm}$ cover depth. The loss of service life was over $90 \%$.

The strategy adopted in this paper is to present first the relationship between the oxygen permeability and concrete characteristics, such as $w / c$ ratio and compressive strength, for several concrete mixtures with a varying $w / c$ ratio. The same tests were also carried out in carbonated specimens. Therefore, the effect of carbonation reaction on the oxygen permeability of concrete has been also investigated. 


\section{Experimental program}

\subsection{Materials}

Three classes of aggregates were used $0 / 4,4 / 8$ and 8/16 with Portland cement CEMII 52.5. Fine sand 0/1 class was used to correct the fineness modulus of sand $0 / 4$ class. Various tests were carried out for the identification of the characteristics of these materials. The test results have showed that these materials are acceptable for manufacturing hydraulic concrete.

In this case study six concrete mixtures were designed. These mixtures correspond to different compressive strength classes determined on standard cylindrical specimens $150 \times 300 \mathrm{~mm}^{2}$ at 28 days. These specimens were conserved and tested in accordance to well-regulated specifications and procedures [26, 27]. The different results of the concrete mixtures proportions and basic properties are given in Table 1. The mixtures design followed the Goerge-Dreux method [28].

In this investigation, two types of specimens were prepared for the tests, cubic specimens $100 \times 100 \mathrm{~mm}^{2}$ and cylindrical specimens $150 \times 100 \mathrm{~mm}^{2}$ sawn from $150 \times 300$ $\mathrm{mm}^{2}$ specimens. The cube specimens are for assessing the concrete compressive strength while cylindrical specimens are for evaluating the concrete oxygen permeability and weight variation.

\subsection{Testing procedures}

The oxygen permeability was assessed using a test method developed by Talah and Kharchi [29]. In particular, the proposed device differs from other devices by the cell (see Fig. 1), which is the main element of the experimental procedure as well as by the elimination of the confining pressure and air cylinder. The test measurement of this method is based on the determination of the apparent permeability coefficient ka, in (m2) calculated using Eq. (1).
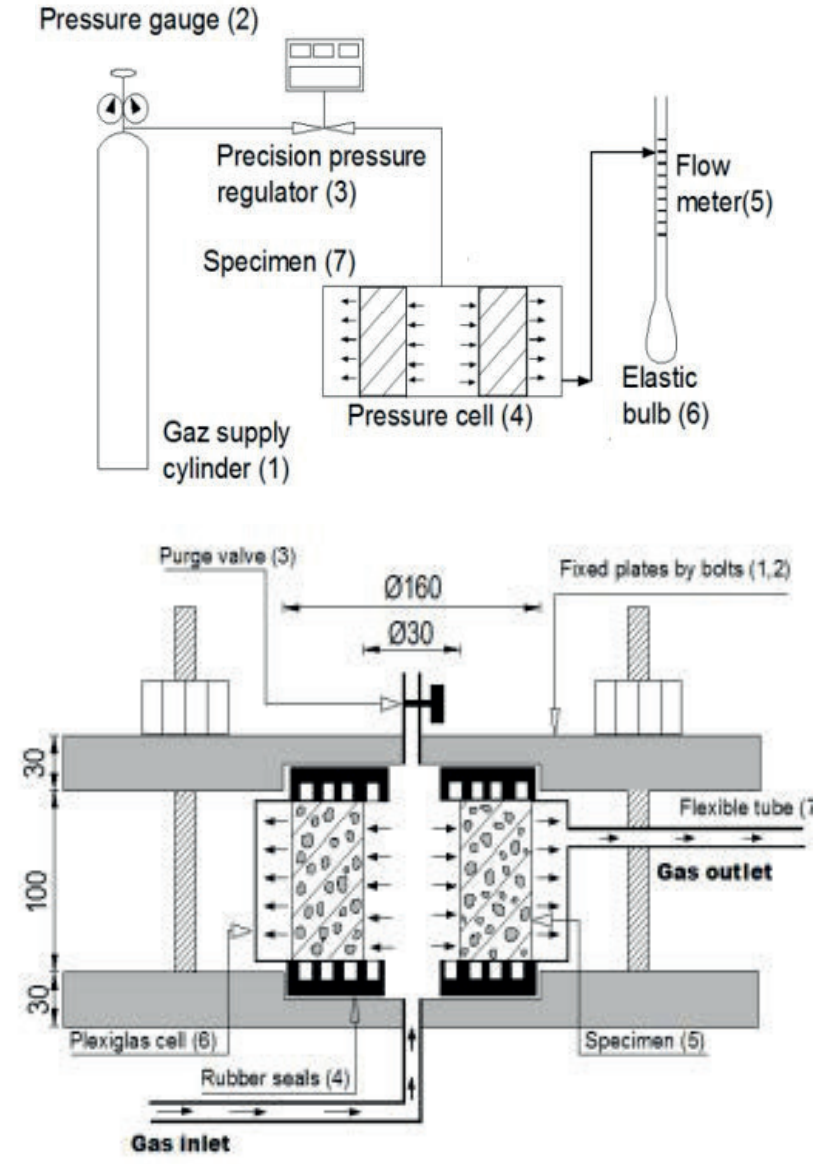

Fig. 1 Oxygen permeability device and cell details [29]

$$
k_{a}=\frac{2 x Q x P_{a t m}\left(R_{2}^{2}-R_{1}^{2}\right) x \mu}{\left(P^{2}-P_{a t m}^{2}\right) \pi x h x\left(R_{2}-R_{1}\right)},
$$

Where $h$ is the specimens thikness (m), $Q$ is the gas debit $\left(\mathrm{m}^{3} / \mathrm{s}\right), P$ and $P_{\text {atm }}$ are the inlet and outlet (atmospheric) pressure respectively $\left(\mathrm{N} / \mathrm{m}^{2}\right), R_{2}$ and $R_{1}$ are the inner and outer radius, respectively, of the concrete specimen (m), $\mu$ is the gas dynamic viscosity $\left(\mathrm{Ns} / \mathrm{m}^{2}\right)$, for the oxygen which was the gas used in this test $\mu=20.2 \times 10^{-6} \mathrm{Ns} / \mathrm{m}^{2}$ at $20^{\circ} \mathrm{C}$.

Table 1 Proportions and basic properties of concrete mixtures

\begin{tabular}{|c|c|c|c|c|c|c|c|}
\hline & Mixtures & $\mathrm{F} 1$ & $\mathrm{~F} 2$ & F3 & $\mathrm{F} 4$ & F5 & F6 \\
\hline \multirow{6}{*}{ 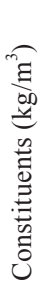 } & CEM II 52.5 & 284.4 & 320 & 355 & 406 & 406 & 420 \\
\hline & Fine Sand 0/1 & 270.9 & 270.9 & 302.7 & 325.8 & 419.6 & 401.7 \\
\hline & Sand $0 / 4$ & 440.9 & 440.9 & 492.5 & 449.4 & 555.5 & 531.9 \\
\hline & Gravel 4/8 & 731.2 & 731.2 & 490.0 & 531.7 & 200.7 & 192.2 \\
\hline & Gravel 8/16 & 414.0 & 414.0 & 510.1 & 444.8 & 705.2 & 675.2 \\
\hline & Silica Fume & / & / & l & / & & 37 \\
\hline & Superplasticizer $(1 / \mathrm{m} 3)$ & / & / & l & / & 6 & 6 \\
\hline & $\mathrm{w} / \mathrm{c}$ & 0.76 & 0.60 & 0.56 & 0.50 & 0.39 & 0.36 \\
\hline & Slump (mm) & 80 & 73 & 82 & 75 & 230 & 210 \\
\hline & Compressive strength $(\mathrm{Rc})(\mathrm{MPa})$ & 19.75 & 29.17 & 32.83 & 33.17 & 46.34 & 58.1 \\
\hline & Standard deviation $(\mathrm{MPa})$ & 0.27 & 0.79 & 2.52 & 1.16 & 0.69 & 1.40 \\
\hline
\end{tabular}



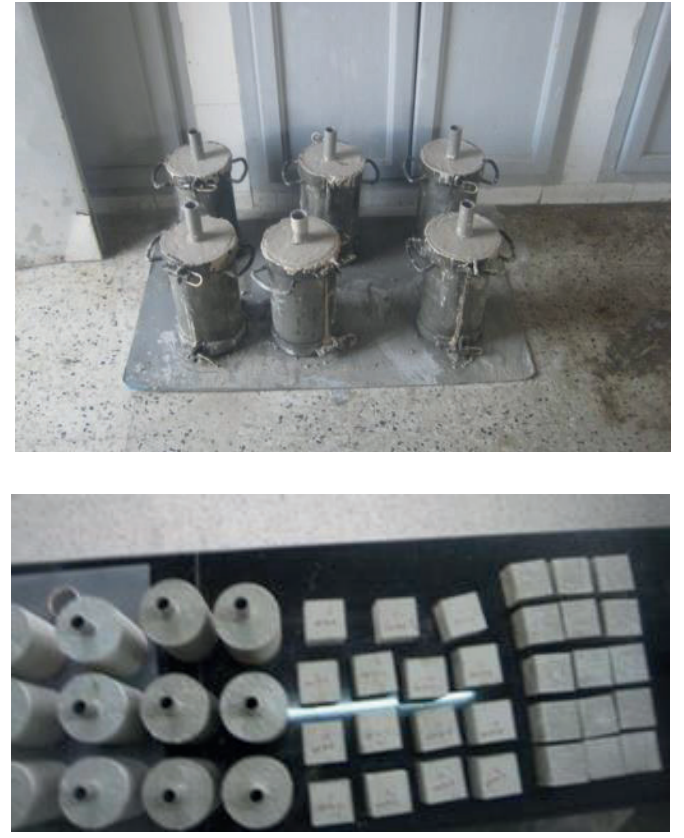

Fig. 2 Cylindrical and cubic specimens prepared for the tests

As mentioned before the specimens that have been used to determine the oxygen permeability were cylindrical $150 \times 100 \mathrm{~mm}^{2}$. The originality of this method resides in the assessment of the oxygen permeability through hollow cylindrical specimens which reflects the actual construction practices [29]. The holes were realized by using a plastic pipe of $30 \mathrm{~mm}$ diameter in order to have an accurate thickness of $60 \mathrm{~mm}$ to be crossed by the oxygen. The different specimens prepared for testing are shown in Fig. 2.

All the specimens were kept 28 days in the laboratory condition and packaged with impermeable film to avoid natural carbonation. Subsequently, they were stored for a period of 8 months along with the cubic specimens under the laboratory conditions (i.e., at $20^{\circ} \mathrm{C} \pm 5$ and $\mathrm{RH}$ between 65 and $75 \%$ ).

Before starting the accelerated carbonation test, the compressive strength and oxygen permeability were first assessed through respectively non-carbonated cubic and cylindrical specimens. The cylindrical and cubic specimens were prepared to the carbonation test according to the French Standard XP P18-458 [30] and covered with double layer of adhesive aluminum to allow unidirectional carbonation penetration. It is worth to note that the direction of the oxygen flux during the permeability test is the same as for accelerated carbonation which is perpendicular to the casting direction.

An accelerated carbonation chamber with volume of $700 \mathrm{~L}$ (Fig. 3) was manufactured for this study at the National Center of Studies and Integrated Research on
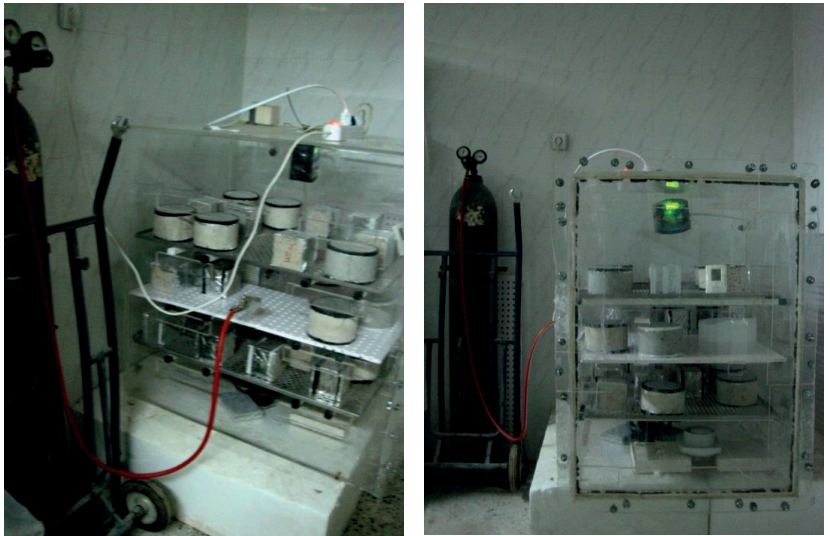

Fig. 3 Accelerated carbonation chamber

Building Engineering (CNERIB), Algiers, Algeria. As suggested in $[30,31]$ the specimens were placed in the accelerated carbonation chamber at $20{ }^{\circ} \mathrm{C}$ and $65 \pm 5 \% \mathrm{RH}$ with a $\mathrm{CO}_{2}$ content of $50 \pm 5 \%$. The RH was kept constant using a saturated saline solution of sodium nitrate. The $\mathrm{CO}_{2}$ percentage during the experiment was determined using a detector of $\mathrm{CO}_{2}$, type CTX 300 with a range of detection varying between 0 and $100 \%$. Regular verification has been made in order to maintain $50 \%$ of $\mathrm{CO}_{2}$ so that the specimens stay under the same conditions during the testing.

In two different stages, and for each concrete mixture, 3 cubes and 3 cylinders were taken from the chamber to testing rig. Before measuring the carbonation depth through spraying phenolphthalein solution on fresh broken concrete specimens [30], oxygen permeability and weight have been assessed on the same cylindrical specimens.

\section{Results and discussion}

\subsection{Determination of the intrinsic permeability}

In this paper, the permeability of concrete is expressed through the intrinsic permeability coefficient (kint). The calculation of the intrinsic permeability coefficient is done by applying the Klinkenberg method [32]. The relationship between apparent and intrinsic permeability is given by the formula below, Eq. (2).

$k_{a}=k_{\mathrm{int}} \times\left(1+\frac{\beta}{P_{m}}\right)$

Where, $\beta$ is the Klinkenberg coefficient; $P_{m}$ is the mean pressure, calculated via using Eq. (3).

$P_{m}=\frac{P+P_{a t m}}{2}$

Where $P$ is the inlet (absolute) pressure of gas and $P_{a t m}$ is the outlet (atmospheric) pressure. 

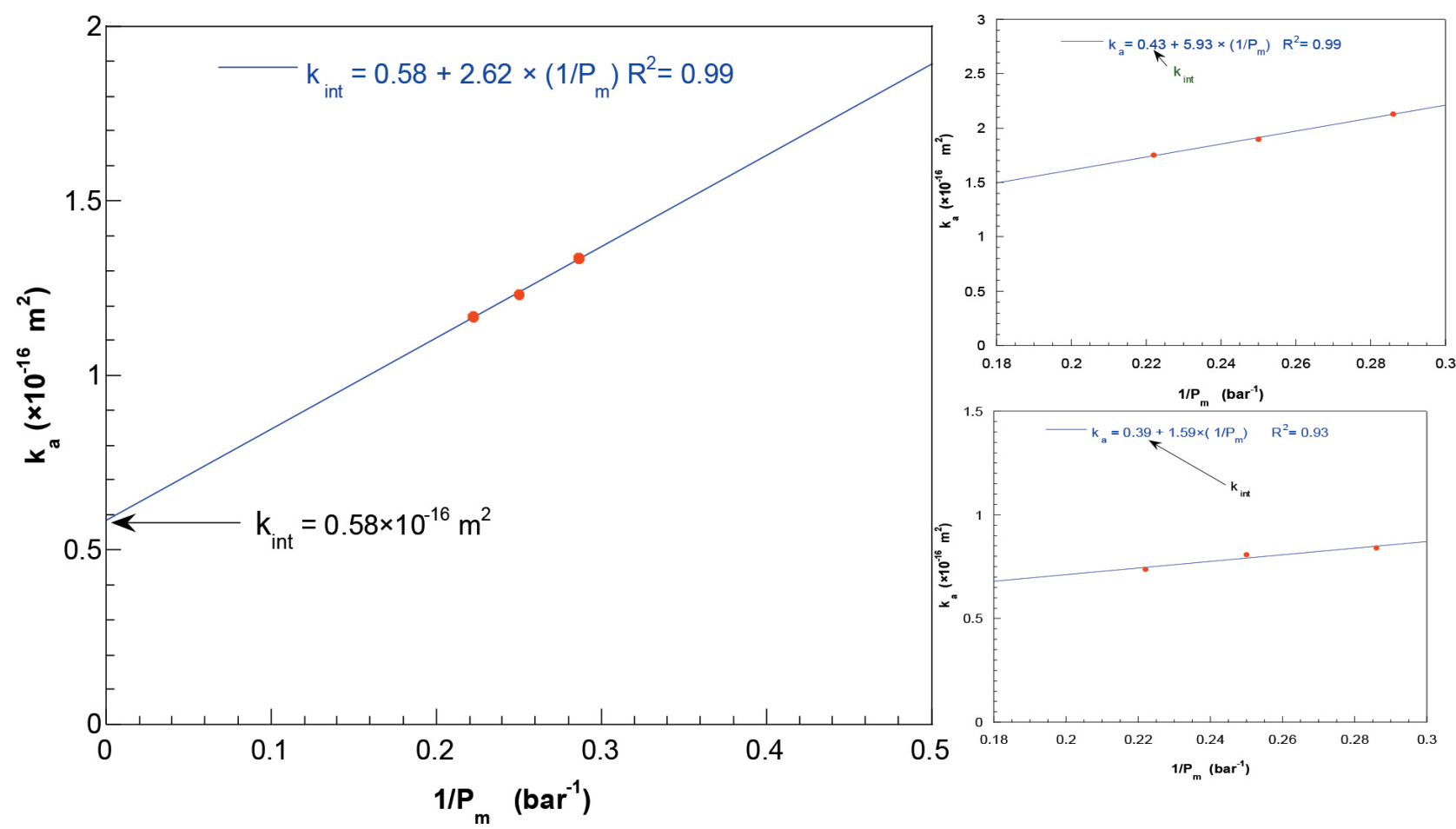

Fig. 4 Some result obtained from experimental measurement of the oxygen permeability for non-carbonated concrete F1 mixture (left) and carbonated specimens F4 mixtures (right)

The method used for determining the intrinsic permeability coefficient, consists of measuring $k_{a}$ via Eq. (1) at different pressures three different pressures at least, and plotting it against the inverse of the mean pressure. Therefore, the intrinsic permeability coefficient is defined as the y-intercept of the line connecting the permeability and the inverse of the mean pressure $P_{m}$ (see Fig. 4). According to [33] the intrinsic permeability value can be a better parameter for characterization of a concrete for durability compared to the traditional Darcy's coefficient of permeability, as it is independent of the fluid properties and the applied pressure gradient.

\subsection{Some of the oxygen permeability correlations with concrete characteristics}

Test results depicted in Fig. 5 show the oxygen intrinsic permeability results determined at 28 days on non-carbonated concrete for the different concrete mixtures versus $w / c$ ratio. Besides, the relationship between $w / c$ ratio and oxygen intrinsic permeability is also highlighted.

Through the results depicted in Fig 5, it can be seen that $\mathrm{w} / \mathrm{c}$ ratio is inversely proportional to the oxygen intrinsic permeability of concrete. According to [1, 19, 34, 35] concrete with low $w / c$ ratio result a denser cement matrix with low total porosity and less continued pore in concrete.

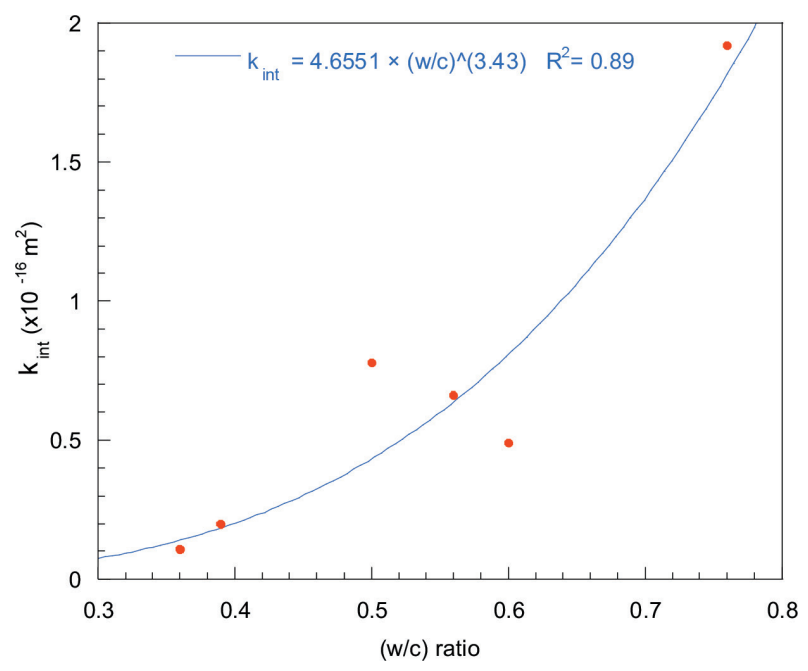

Fig. 5 Oxygen intrinsic permeability of concrete vs. $w / c$ ratio

The relationship between $w / c$ ratio and the concrete oxygen intrinsic permeability was obtained by regression analysis. According to [36] power regression analysis was used for the three different cement types to express the relationships between permeability coefficient and $w / c$ ratio. The coefficients of determination $\left(R^{2}\right)$ found by the authors were over 0.9. In this case, and following [36], power regression analysis is adopted also to express the relationship. The regression analysis result shows that good relationship exists between kint and $w / c$ ratio with a coefficient of determination $R^{2}$ equal to 0.89 (see Fig. 5). 
In order to further characterize the concrete mixtures prior to the accelerated carbonation test the relationship between the compressive strength $\left(R_{c}\right)$ and the oxygen intrinsic permeability determined at 28 days has been derived. Following [37] a general relationship between the oxygen permeability coefficient and $R_{c}$ has been found. The shape of the regression function is as follows: $Y=a X^{b}$ where $Y$ and $X$ are the permeability coefficient and the compressive strength, respectively; $\mathrm{a}$ and $\mathrm{b}$ are constants. After that, for the same relationship, the same power function has been used by Bondar et al. [38]. In this case, power regression analysis has been selected to express the relationship. The function obtained through the regression analysis is presented in Fig. 6. The coefficient of determination $R^{2}$ found equal to 0.94 , which indicates that good relationship exists between $k_{i n t}$ and $R_{c}$.

\subsection{The effect of carbonation reaction on the concrete compressive strength}

The evolution of the compressive strength values measured on cubic specimens $\left(100 \times 100 \mathrm{~mm}^{2}\right)$ as a function of carbonation depth is depicted in Fig. 7.

As shown by the figure, the carbonation reaction considerably affects the concrete compressive strength. As the carbonation depth increases the concrete compressive strength increases. This result is in accordance with the findings reported in [39]. The percentage of the strength increase is generally related to the rate of carbonation where the concrete mixture $\mathrm{F} 3$ has reached an $88 \%$ increase of its compressive strength which corresponds to the highest carbonation depth.

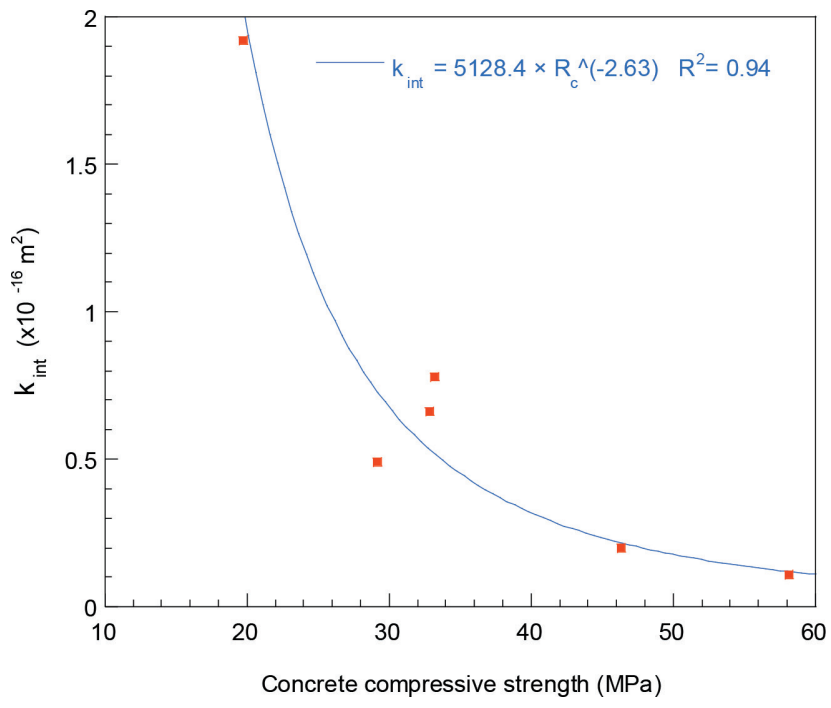

Fig. 6 Oxygen intrinsic permeability versus concrete compressive strength
The increase of compressive strength observed in this study following Thiery [19] is due to the carbonation reaction that causes the reduction of the porosity and formation of new crystals with high strength which in turn leads to an improvement in the mechanical performance of the material. The formed mineral $\mathrm{CaCO}_{3}$ consolidates the microstructure since calcium carbonate is recognized as an excellent binder. This result can also be explained by assessing the weight changes before and after carbonation. In this case, the results of weight variation with respect to the carbonation depth of all concrete mixtures are shown in Fig. 8.

Test results presented in Fig. 8 show that all concrete mixtures have weight gain and the weight of the concretes mixtures proportionally increase with the carbonation depth. The highest value of the weight gain corresponds to the highest carbonation depth. The high-performance concrete mixtures F5 and F6 show a larger weight gains with carbonation when compared with the other ordinary concrete mixtures.

According to Chabil [34] the process of carbonation leads to the formation of above mentioned compound (i.e, $\mathrm{CaCO}_{3}$ ) having high molar volume $\left(36.9 \mathrm{~cm}^{3} / \mathrm{mol}\right)$ compared with $\mathrm{Ca}(\mathrm{OH})_{2}$ which has a molar volume equal to $33.1 \mathrm{~cm}^{3} / \mathrm{mol}$. The increases of the specimen's weight after carbonation substantiate the increase of the concrete compressive strength.

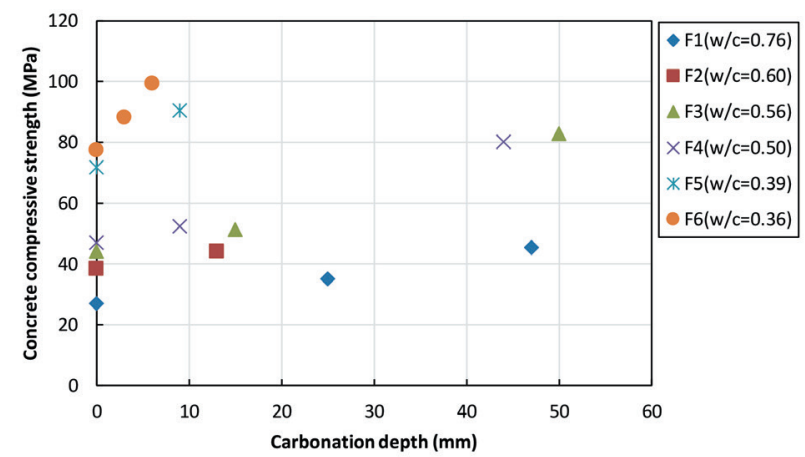

Fig. 7 Concrete compressive strength as function of carbonation depth

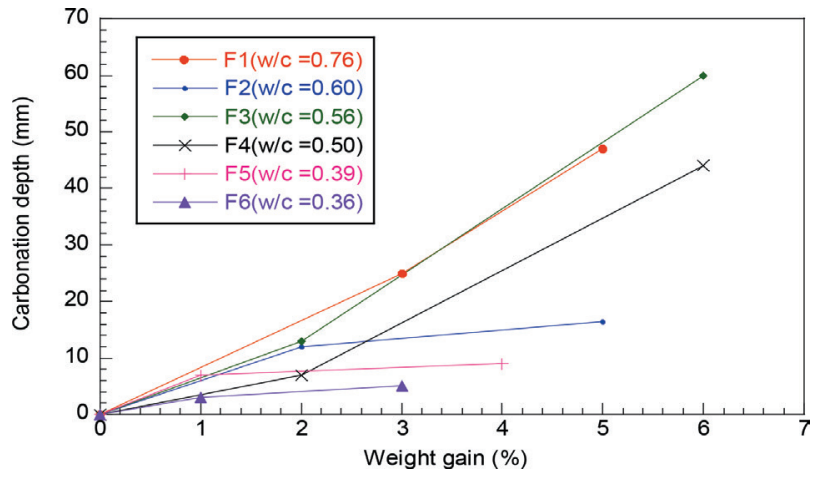

Fig. 8 Carbonation depth versus the concrete weight gain 
Furthermore, exponential regression analysis of the results depicted in Fig. 8 showed that the weight gain can be an approximate indication for the carbonation depth with a coefficient of determination $R^{2}$ equal to 0.74 .

\subsection{The effect of carbonation reaction on the concrete oxygen permeability}

For the different concrete mixtures, the evolution of the relative intrinsic permeability expressed as function of the carbonation depth is given in Fig. 9.

Two different behaviors were observed that conduct, to two different relationships. The regression analysis shown in red line is for concrete mixtures F5 and F6 results while, the blue line concerns the regression analysis of the concrete mixtures F1, F2, F3 and F4 results. Test results show that the carbonation reaction considerably affects the concrete permeability as carbonation increases the permeability of concrete increases. These results are observed in all concrete mixtures. This increase in permeability due to carbonation is also obtained by Russel [20] and in some mixtures by Thiery [19]. Furthermore, it can be seen that the effect of carbonation on the permeability depend of the compressive strength. High performance concrete is more influenced by carbonation in comparison with ordinary concrete. This has been observed also where the influence of carbonation on the compressive strength was analyzed (Fig. 7). Linear regressions of the ordinary concrete mixtures and high performance concrete mixtures were also performed. The regression analysis showed existence of good correlation with coefficient of determination $\mathrm{CoD}\left(R^{2}\right)$ equal to 0.75 and 0.97 .

Thiery has observed in some mixtures this trend and explained that carbonation reaction caused the reduction of porosity but in the same way this reaction creates larger pores with a new and high intercommunication pore structure after the formation of the $\mathrm{CaCO}_{3}$ which can be the reason of the oxygen intrinsic permeability increase. Also, the mercury intrusion test results have been done by Thiery supports this finding.

On the concrete mixture F1 where a carbonation depth equal to $25 \mathrm{~mm}$, the carbonated zone and non-carbonated zone have been analyzed via SEM images. Test results show that carbonation reaction affects the porosity system which leads to the creation of macro porosity that can probably affect the interconnectivity of the concrete pore system. This phenomenon is clear in the SEM images shown in Fig. 10. This result supports the increase of the concrete oxygen permeability that has been observed herein for the carbonated concrete. The arrows presented on the SEM image (b) indicate the $\mathrm{CaCO}_{3}$ formation after consummation of the $\mathrm{Ca}(\mathrm{OH})_{2}$.

The porosity of the SEM images presented in Fig. 10 was determined. The used program is Image-J, an open source software. This program is also used by several researchers to determine the porosity and the ratio between the

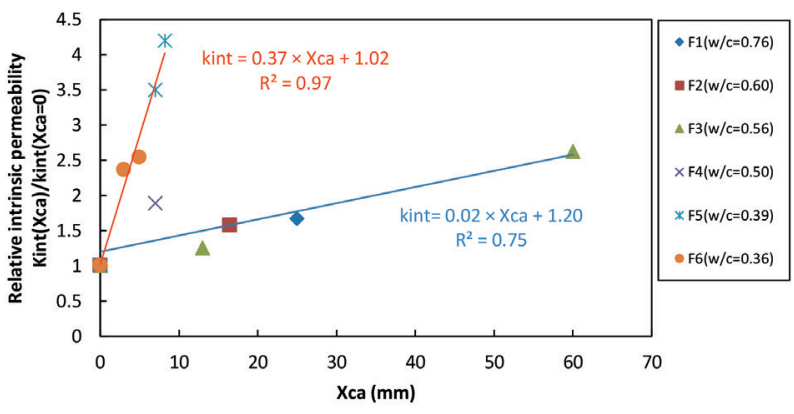

Fig. 9 Oxygen intrinsic permeability versus carbonation depth
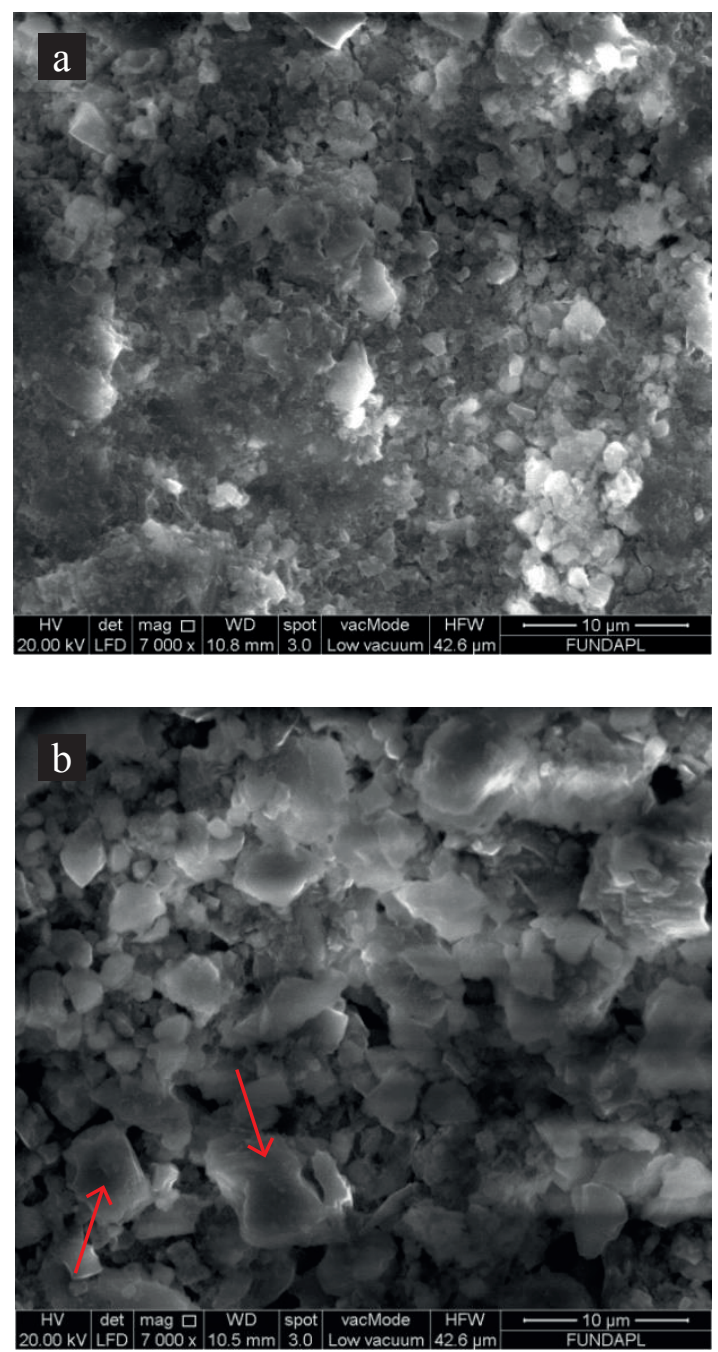

Fig. 10 SEM images of concrete mixture F1 with $w / c$ ratio equal to 0.76 and $X_{c}$ equal to $25 \mathrm{~mm}$ for a) non-carbonated and b) carbonated zones 
aggregate and the binder of the historical mortars [40, 41]. A threshold of the grey levels allowed isolating the holes as shown in Fig. 11. Therefore, the software made the automatic count of the holes (black) and sums their total area.

The porosity of carbonated and non-carbonated zones is respectively, $6.24 \%$ and $1.62 \%$. The obtained values explain that carbonation reaction affects the permeability of concrete with the creation of larger pores due to the consummation of $\mathrm{Ca}(\mathrm{OH})_{2}$ and formation of calcite which in turn lead to the increase of permeability.

For the same carbonated zone where MEB analysis has been carried out, X-ray diffraction (XRD) analysis has also been performed. The results depicted in Fig. 12 shows the total consummation of $\mathrm{Ca}(\mathrm{OH})_{2}$. The highest pick is at $27^{\circ} 2 \theta$ corresponds to the calcite (C), precisely vaterite (PDF 24-003D) with percentage of $74.3 \%$. The other picks correspond to other minerals such as calcium silicate hydrate (CSH) (PDF 29-0373) and calcium silicate (CS) (PDF 18-0.306).
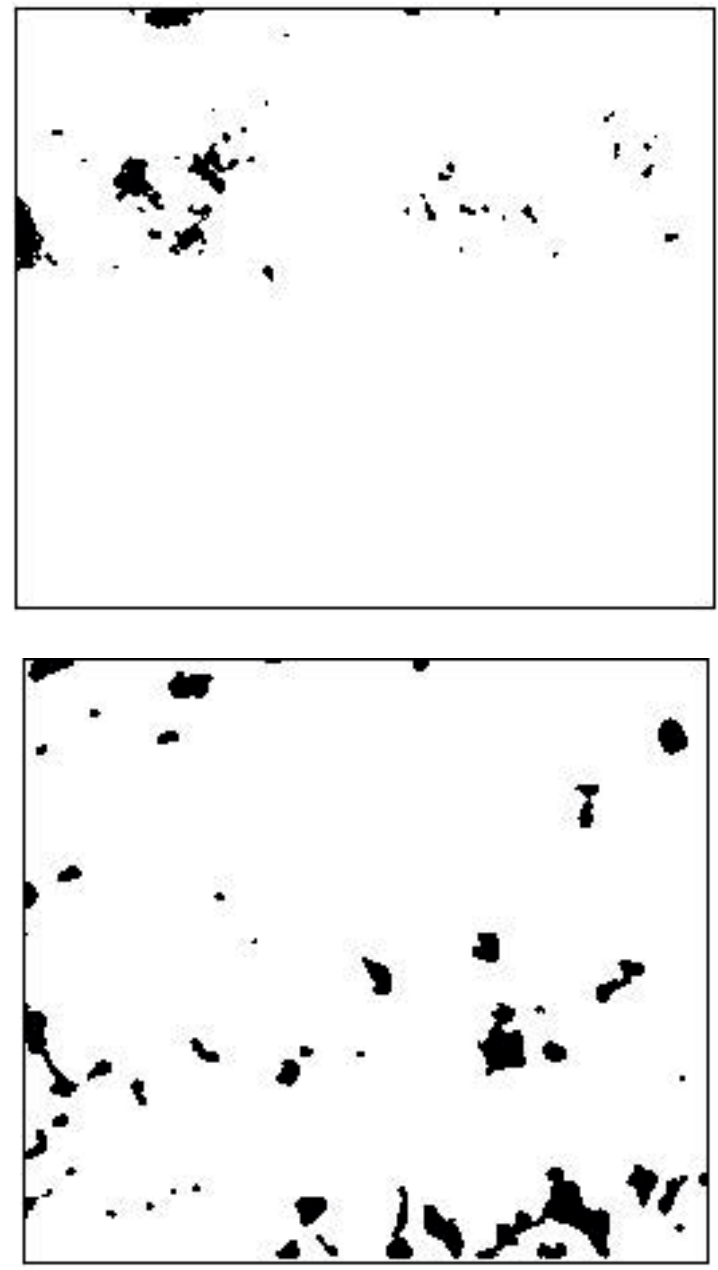

Fig. 11 Binary images of the pores to determine the porosity of the noncarbonated (up) and carbonated zones (down)

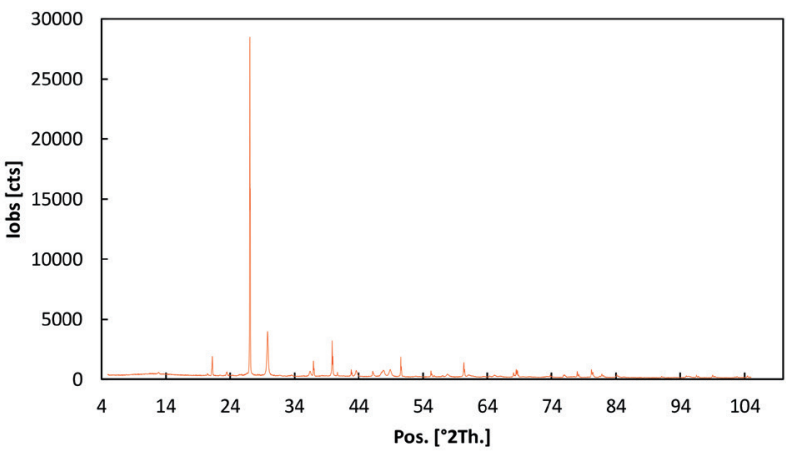

Fig. 12 X-ray diffraction (XRD) patterns of the carbonated zone for the concrete mixture F1

\section{Conclusions}

The main goal of this paper is to clarify the controversy that exists of the effect of carbonation reaction on the permeability of concrete. For several concrete mixtures with w/c ratio ranging between 0.76 and 0.36 the influence of the carbonation reaction on the concrete oxygen permeability, compressive strength and concrete porosity has been experimentally studied. The conclusions that can be drawn from this investigation are as follows:

For the non-carbonated concrete the assessment of the oxygen permeability through the $w / c$ ratio and compressive strength shows the existence of good correlations with coefficients of determinations equal to 0.88 and 0.92 , respectively.

The carbonation reaction has a positive effect on the concrete compressive strength where the fully carbonated concrete has the highest gain in compressive strength. Furthermore, it was observed that high performance concrete is more influenced by carbonation in comparison with ordinary concrete.

The concrete carbonation reaction led to the formation of new elements that induce the compressive strength and the concrete weight to increase. These results are observed for all concrete mixtures.

The results obtained showed that permeability increases as carbonation progresses. Furthermore, this increase depends on the compressive strength of concrete and the effect of carbonation of the oxygen permeability is more significance in high performance concrete rather in ordinary concrete.

SEM images justify the increase of the oxygen permeability via the observation of the creation of larger porosity that influences the interconnectivity of the pore system

The results reported herein provided valuable insights on the effect of carbonation on the permeability of concrete mixtures using one type of cement. The differences 
between the effect of carbonation in high performance and ordinary concretes should to be considered when developing a model for service life prediction. Further research studies adopting other type of cement are needed for further generalization and understanding.

\section{References}

[1] Chaussadent, T. "État des lieux et réflexions sur la carbonatation du béton armé", (State of the Art and reflections on the carbonation of reinforced concrete), Laboratoire Central des Ponts et Chaussées, Paris, France, 1999. [online] available at: https://www.ifsttar. fr/fileadmin/user_upload/editions/lcpc/ERLPC/ERLPC-OALCPC-OA29.pdf (in French)

[2] Davalos, J. F. "Advanced materials for civil infrastructure rehabilitation and protection", In: Seminar at the City College of New York, New York, NY, USA, 2012.

[3] O'Connell, M., McNally, C., Richardson, M. G. "Biochemical attack on concrete in wastewater applications: state of the art review", Cement and Concrete Composites, 32(7), pp. 479-485, 2010. https://doi.org/10.1016/j.cemconcomp.2010.05.001

[4] Monteiro, I., Branco, F. A., de Brito, J., Neves, R. "Statistical analysis of the carbonation coefficient in open air concrete structures", Construction and Building materials, 29, pp. 263-269, 2012. https://doi.org/10.1016/j.conbuildmat.2011.10.028

[5] Branco, F. A., de Brito, J. "Handbook of Concrete Bridge Management", ASCE Press, Reston, VA, USA, 2004. https://doi.org/10.1061/9780784405604

[6] Neves, R., Sena da Fonseca, B., Branco, F., de Brito, J., Castela, A., Montemor, M. F. "Assessing concrete carbonation through air permeability measurements", Construction and Building Materials, 82, pp. 304-309, 2015.

https://doi.org/10.1016/j.conbuildmat.2015.02.075

[7] Raharinaivo,A., Arliguie, G., Chaussadent, T., Grimaldi, G., Pollet, V., Taché, G. "La corrosion et la protection des aciersdans le béton" (Corrosion and protection of steels in concrete), Presses de l'École Nationale des Pontset Chaussées, Paris, France, 1998. (in French) [online] Available at: http://cdoc.ensm-douai.fr/emdcat/DetailDoc. aspx?DocID $=61908$

[8] Zhiguon, N., Ri, Y. "Experimental investigation of concrete carbonation under different conditions", Study of Civil Engineering and Architecture (SCEA), 2(4), 2013.

[9] Papadakis, V. G., Vayengas, C. G., Fardis, M. N. "Fundamental Modeling and Experimental Investigation of Concrete Carbonation", ACI Materials Journal, 88(4), pp. 363-373, 1991. https://doi.org/10.14359/1863

[10] Zhang, X., Zhou, X., Zhou, H., Gao, K., Wang, Z. "Studies on forecasting of carbonation depth of slag high performance concrete considering gas permeability", Applied Clay Sience, 79, pp. 36-40, 2013. https://doi.org/10.1016/j.clay.2013.02.020

[11] Zhao, H., Sun, W., Wu, X., Gao, B. "The Effect of the Material Factors on the Concrete Resistance Against Carbonation", KSCE Journal of Civil Engineering, 22(4), pp. 1265-1274, 2018. https://doi.org/10.1007/s12205-017-0988-9

\section{Acknowledgments}

The authors acknowledge the National Center of Studies and Integrated Research on Building Engineering (CNERIB) for supplying the aggregates and for providing the appropriate testing environment during this experimental campaign.

[12] Bernal, S. A., Provis, J. L., de Gutiérrez, R. M., van Deventer, J. S. J. "Accelerated carbonation testing of alkali- activated slag/metakaolin blended concretes: effect of exposure conditions", Materials and Structures, 48, pp. 653-669, 2015. https://doi.org/10.1617/s11527-014-0289-4

[13] Ashraf, W. "Carbonation of cement-based materials: Challenges and opportunities", Construction and Building Materials, 120, pp. 558-570, 2016. https://doi.org/10.1016/j.conbuildmat.2016.05.080

[14] fib "Model Code for Service Life Design", fib Bulletin, 34, Fédération Internationale du Béton, Lausanne, Switzerland, 2006. https://doi.org/10.35789/fib.BULL.0034

[15] LNEC "LNEC E 465 Concrete. Methodology for estimating the concrete performance properties allowing to comply with the design working life of the reinforced or prestressed concrete structures under the environmental exposures XC and XS", National Laboratory for Civil Engineering, Lisbon, Portugal, 2005.

[16] Neves, R., Branco, F. A., de Brito, J. "A method for the use of accelerated carbonation tests in durability design", Construction and Building Materials, 36, pp. 585-591, 2012. https://doi.org/10.1016/j.conbuildmat.2012.06.028

[17] Dawaele, P. J., Reardon, E. J., Dayal, R. "Permeability and porosity changes associated with cement grout carbonation", Cement and Concrete Research, 21(4), pp. 441-454, 1991. https://doi.org/10.1016/0008-8846(91)90092-v

[18] Song, H.-W., Kwon, S.-J. "Permeability characteristics of carbonated concrete considering capillary pore structure", Cement and Concrete Research, 37(6), pp. 909-915, 2007.

https://doi.org/10.1016/j.cemconres.2007.03.011

[19] Thiery, M. "Modélisation de la carbonatation atmosphérique des matériaux cimentaires, Prise en compte des effetscinétiques et des modifications microstructurales et hydrique" (Modeling of carbonatationatmosphérique of the auxiliary materials, Prize in compte des effets cinétiques et microstructurales modifications et hydrique), PhD Thesis, Ecole Nationale Des Ponts et Chaussées, 2005. [online] Available at: https://pdfs.semanticscholar.org/cd97/ 012119f376466ac20cd7936a547652c4ea81.pdf (in French)

[20] Russell, D., Basheer, P. A. M., Rankin, G. I. B., Long, A. E. "Effect of relative humidity and air permeability on prediction of the rate of carbonation of concrete", Structures and Building, 146(3), pp. 319-326, 2001. https://oi.org/10.1680/stbu.2001.146.3.319

[21] Torrent, R. J. "A two-chamber vacuum cell for measuring the coefficient of permeability to air of the concrete cover on site", Materials and Structures, 25, pp. 358-365, 1992. https://doi.org/10.1007/bf02472595 
[22] Salvoldi, B. G., Beushausen, H., Alexander, M. G. "Oxygen permeability of concrete and its relation to carbonation", Construction and Building Materials, 85, pp. 30-37, 2015.

https://doi.org/10.1016/j.conbuildmat.2015.02.019

[23] Castel, A., François, R., Arliguie, G. "Effect of loading on carbonation penetration in reinforced concrete elements", Cement and Concrete Research, 29(4), pp. 561-565, 1999. https://doi.org/10.1016/s0008-8846(99)00017-4

[24] Yao, Y., Wang, L., Folker, W. H. "Publications on Durability of Reinforced Concrete Structures under Combined Mechanical Loads and Environmental Actions: An Annotated Bibliography", Rilem, Paris, France, Rep. 043, 2013. [online] Available at: https://www. rilem.net/publication/publication/427

[25] den Heede, P. V., Belleghem, B. V., Keersmaecker, M. D., Adriaens, A., de Belie, N."Sustainability effects of including concrete cracking and healing in service life prediction for marine environments", presented at Fourth International Conference on Sustainable Construction Materials and Technologies (SCMT4), Las Vegas, NA, USA, Aug. 7-11, 2016

http://www.claisse.info/Proceedings.htm

[26] IANOR "NA 17004 Assessment of the compressive strength on site of structures and prefabricated concrete elements", Algerian Institute for Standardization, Alger, Algeria, 2008.

[27] IANOR "NA 16002 Specifications, performances, production and conformity", Algerian Institute for Standardization, Alger, Algeria, 2007.

[28] Festa, J., Dreux, G. "New guide of concrete and its constituents", 8th ed., Eyrolles, Paris, France, 1998. (in French)

[29] Talah, A., Kharchi, F. "A Modified Test Procedure to Measure Gas Permeabilityof Hollow Cylinder Concrete Specimens", International Journal of Engineering and Technology, 5(1), pp. 91-94, 2013. https://doi.org/10.7763/ijet.2013.v5.518

[30] AFNOR "XP P18-458Tests for hardened concrete - Accelerated carbonation test - Measurement of the thickness of carbonated concrete", AFNOR Group, Paris, France, 2008.

[31] Arliguie, G., Hornaim, H. "GranDuBé: Grandeurs associées à la durabilité des bétons" (GranDuBé Quantities associated with the durability of concrete), Presses des Ponts, Paris, France, 2007. (in French)
[32] Klinkenberg, L. J. "The Permeability of Porous Media to Liquid and Gas", In: Drilling and Productions Practices, American Petroleum Institute, Washington, DC, USA, 1941, pp. 200-213.

[33] Abbas, A., Carcasses, M., Ollivier, J.-P. "Gas permeability of concrete in relation to its degree of saturation", Material and Structures, 32, pp. 3-8, 1999. https://doi.org/10.1007/BF02480405

[34] Chabil, F.-Z. D. "Carbonatation des betons adjuvantes a base de resources locales Algeriennes" (Carbonation of concrete admixtures at the base of Algerian local resources), $\mathrm{PhD}$ Thesis, Université d'Orléans, Université de Constantine, 2009. [online] Available at: https://tel.archives-ouvertes.fr/tel-00797822/document (in French)

[35] Neves, R. "Concrete air permeability and carbonation in structures", $\mathrm{PhD}$ Thesis, Technical University of Lisbon, 2012. (in Portuguese)

[36] Tracz, T., Śliwiński, J. "Influence of cement type and water-cement ratio on open porosity and gas permeability of cement pastes", In: UKIERI Concrete Congress Innovation Concrete Construction, Jalandhar, India, 2013, pp. 461-470.

[37] Costa, U., Fucoetti, M., Massazza, F. "Permeability and Diffusion of Gasses in Concrete", In: Proceedings of the 9th International Congress of Chemistry of Cement, New Delhi, India, 1992, pp. 107-114.

[38] Bondar, D., Lynsdale, C. J., Milestone, N. B., Hassani, N. "Oxygen and Chloride Permeability of Alkali-Activated Natural Pozzolan Concrete", ACI Materials Journal, 109(1), pp. 53-62, 2012. https://doi.org/10.14359/51683570

[39] Chang, C.-F., Chen, J.-W. "Strength and elastic modulus of carbonated concrete", ACI Materials Journal, 102(5), pp. 315-321, 2005. https://doi.org/10.14359/14710

[40] Moshella, M. E., Canavesio, W., Cristellotti, M., Costa, M. "Investigation about ancient mortars and plasters in the Mondovì cathedral (Cuneo, Italy)", Periodica di Mineralogia, 82(3), pp. 429-442, 2013. https://doi.org/10.2451/2013PM0025

[41] Middendorf, B., Schade, T., Kraus, K. "Quantitative Analysis of Historic Mortars by Digital Image Analysis of Thin Sections", Restoration of Buildings and Monuments, 23(2), pp. 83-92, 2017. https://doi.org/10.1515/rbm-2016-0011 